\title{
Ectopic pregnancy in an undescended fallopian tube: a diagnostic challenge
}

\author{
Catarina Pardal, Luís Braga, Belisa Vides
}

Gynecology and Obstetrics Department, Hospital de Braga, Braga, Portugal

\section{Correspondence to} Dr Catarina Pardal, catarinapardal_84@hotmail. com

Accepted 25 January 2016

\section{SUMMARY}

Uterine malformations are the most frequent anomalies of the Müllerian ducts, but undescended ovaries and fallopian tubes are very rare congenital defects. Pregnancy in these misplaced organs may occur, frequently posing a diagnostic challenge. A case of a ruptured ectopic pregnancy in an undescended fallopian tube associated with other genital malformations is presented. This case provides evidence for the recognised phenomenon of peritoneal gametes or embryo transmigration.

\section{BACKGROUND}

Development of the female genital tract is a complex process. It is dependent on a series of events such as cellular differentiation, migration, fusion and canalisation. Failure of any of these processes may result in a congenital anomaly. Uterine abnormalities are the most frequent anomalies of the Müllerian ducts, occurring in $2-4 \%$ of fertile women, ${ }^{1}$ while structural anomalies of the fallopian tubes and ovaries are exceedingly rare. ${ }^{2}$ Some uterine malformations, in particular unicornuate uterus, ${ }^{1}$ are known to be associated with renal agenesis, ectopic ovaries and undescended tubes, and, although rare, pregnancy in such misplaced organs can occur. These ectopic pregnancies are frequently difficult to diagnose and are associated with important maternal morbidity and mortality.

\section{CASE PRESENTATION}

A 28-year-old woman presented at our emergency department, with a history of 9 weeks of amenorrhoea, mild vaginal bleeding and pelvic pain. She reported a positive urine pregnancy test. The patient's history was significant for primary infertility. The subsequent evaluation included a diagnostic laparoscopy, which revealed a left unicornuate uterus with no rudimentary horn (Buttram and Gibbons' classification class IIB or European Society of Human Reproduction and Embryology-European Society for Gynaecological Endoscopy (ESHRE/ESGE) classification class U4b) and an absent right fallopian tube and ovary.

On admission, the patient was pale; her blood To cite: Pardal C, Braga L, Vides B. BMJ Case Rep Published online: [please include Day Month Year] doi:10.1136/bcr-2015213058

\section{INVESTIGATIONS}

A transvaginal ultrasound (TVUS) demonstrated a unicornuate uterus with no rudimentary horn, a thickened homogeneous endometrium $(16 \mathrm{~mm})$, no signs of pregnancy (intrauterine or extra uterine) and scarce free peritoneal fluid. No right adnexa were identified. The measurement of the serum $\beta$ subunit human chorionic gonadotrophin ( $\beta$-HCG) was positive $(38485.9 \mathrm{mUI} / \mathrm{mL}$ - high above the discriminatory zone). An abdominal ectopic pregnancy was suspected and the ultrasound (US) confirmed the location of a gestational sac in the right upper quadrant of the abdomen, near what appeared to be a right ectopic ovary.

Given the previous information of absent right adnexa, a laparoscopy was proposed to clarify both the diagnosis and treatment. The main pelvic findings included (video 1) a small volume haemoperitoneum and a unicornuate uterus with normal left adnexa and no right rudimentary horn. The abdominal inspection revealed a right undescended ovary located above the pelvic bream and adherent to the parietal peritoneum, with a juxtaposed bluish sac-like formation $5 \mathrm{~cm}$ in diameter, corresponding to the ectopic pregnancy. No corpus luteum was identified. Histological examination confirmed the diagnosis of ruptured tubal pregnancy.

\section{DIFFERENTIAL DIAGNOSIS}

Amenorrhoea and abdominal pain are common symptoms of early pregnancy complications (such as uterine enlargement, threatened abortion or ruptured corpus luteum cyst), as well as ectopic pregnancy. If in the context of uterine bleeding, another possible diagnosis is gestational trophoblastic disease.

The TVUS plus the high level of serum $\beta$-HCG suggested an ectopic pregnancy of unknown location, which was confirmed by the abdominal US and diagnostic laparoscopy.

\section{TREATMENT}

Laparoscopic right total salpingectomy was performed (video 1). Because the patient had a history of infertility, the ectopic right ovary was not removed.

\section{OUTCOME AND FOLLOW-UP}

The patient's postoperative course was uneventful, and she was discharged 2 days after surgery. 


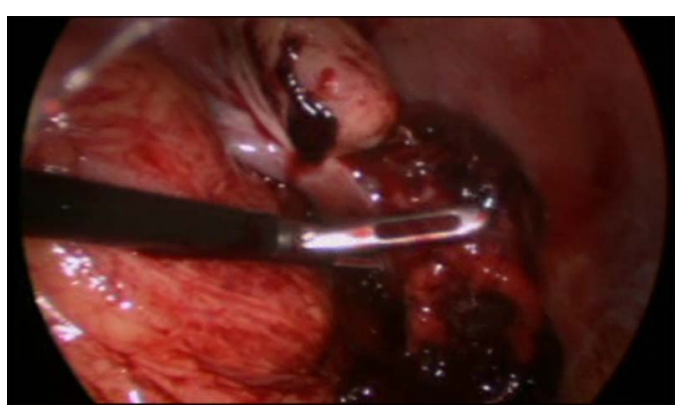

Video 1 Laparoscopic evaluation of the abdomen.

\section{DISCUSSION}

Congenital malformations of the female genital tract are defined as deviations from normal anatomy resulting from embryological maldevelopment of the Müllerian ducts. They represent a rather common benign condition with a prevalence of $4-7 \%{ }^{3}$ Uterine anomalies occur in $2-4 \%$ of fertile women, ${ }^{1}$ but undescended ovaries and fallopian tubes are very rare congenital abnormalities of the Müllerian ducts. ${ }^{4}$ They are not mentioned in the widely used classification of Müllerian anomalies proposed by Buttram and Gibbons in 1979, nor are they included in the new classification proposed by ESHRE/ESGE.

Embryologically, the fallopian tube is the most cephalic portion of the Müllerian duct. During the sixth week of gestation, it can be seen as a shallow depression in the coelomic epithelium lateral to the mesonephric duct. Starting as a groove, the tube forms, a lumen develops and the Müllerian duct grows caudally. The ovary, however, starts as a thickening of the genital ridge during the fifth week. Germ cells found near the allantois migrate towards the genital ridge. The ovary then 'descends' from its position near the kidney towards the true pelvis. $^{2}$ Failure of descent of the ovaries and tubes may occur, and pregnancy in such misplaced organs may pose important maternal risks. ${ }^{2}$ Only a few case reports are found in the literature. Granat and co-authors reported the first case of pregnancy in ectopic adnexa. ${ }^{2}$ Other authors have described such a condition, ${ }^{245}$ varying the site of fallopian tube in the abdomen and site of corpus luteum.

Our case illustrates the interesting anatomic and physiological features of the female genital tract and demonstrates the phenomenon of transperitoneal gamete/embryo migration. Furthermore, this case underlines the importance of careful US examination of both adnexa when an extra uterine pregnancy is suspected, even when a right ovary agenesia and a left unicornuate uterus would appear to exclude the involvement of one side.

Some authors ${ }^{4}$ have proposed the removal of undescended fallopian tubes in order to decrease the risk of a tubal pregnancy, and laparoscopic treatment appears to be a relatively easy and safe procedure.

In summary, an ectopic pregnancy in an undescended fallopian tube is a rare condition frequently difficult to diagnose. There is no simple screening technique for this condition and, therefore, clinicians and radiologists should be aware of it for such a diagnosis.

\section{Learning points}

- Uterine abnormalities are the most frequent congenital anomalies of the Müllerian ducts, while structural anomalies of the fallopian tubes are very rare.

- Ectopic pregnancy in undescended fallopian tubes may occur, posing a diagnostic challenge.

- Pregnancy in undescended fallopian tubes provides supportive evidence for the phenomenon of transperitoneal gamete/embryo migration.

Contributors CP managed the case, provided the design and conception of the article, performed the literature review and is the guarantor. LB managed the case. BV managed the case and revised the article.

Competing interests None declared.

\section{Patient consent Obtained.}

Provenance and peer review Not commissioned; externally peer reviewed.

\section{REFERENCES}

1 Iverson R, DeCherney A, Laufer M. Clinical manifestations and diagnosis of congenital anomalies of the uterus, Uptodate, 2015

2 Seoud M, Khayyat H, Mufarrij IK. "Ectopic pregnancy in an undescended fallopian tube: an unusual presentation". Obstet Gynecol 1987;69(Part 2):455-7.

3 Grimbizis GF, Gordts S, Di Spiezio Sardo A, et al. The ESHRE/ESGE consensus on the classification of female genital tract congenital anomalies. Hum Reprod 2013;28:2032-44.

4 Timmerman D, Lewis B. Laparoscopic treatment of an ectopic pregnancy in an undescended fallopian tube. J Obstet Gynaecol 1993;13:291-2.

5 Gabriel B, Fischer DC, Sergius G. Unruptured pregnancy in a non-communicating heterotopic right fallopian tube associated with left unicornuate uterus: evidence for transperitoneal sperm and oocyte migration. Acta Obstet Gynecol Scand 2002;81:91-2

Copyright 2016 BMJ Publishing Group. All rights reserved. For permission to reuse any of this content visit

http://group.bmj.com/group/rights-licensing/permissions.

BMJ Case Report Fellows may re-use this article for personal use and teaching without any further permission.

Become a Fellow of BMJ Case Reports today and you can:

- Submit as many cases as you like

- Enjoy fast sympathetic peer review and rapid publication of accepted articles

- Access all the published articles

- Re-use any of the published material for personal use and teaching without further permission

For information on Institutional Fellowships contact consortiasales@bmjgroup.com

Visit casereports.bmj.com for more articles like this and to become a Fellow 